\title{
Hubungan Kepatuhan Cuci Tangan Terhadap Kejadian Infeksi Aliran Darah di Unit Neonatal Sebelum dan Setelah Edukasi
}

Mustarim, Rinawati Rohsiswatmo

Departemen Ilmu Kesehatan Anak Fakultas Kedokteran Universitas Indonesia/ RSUPN Cipto Mangunkusumo, Jakarta

Latar belakang. Cuci tangan merupakan strategi efektif menurunkan kejadian infeksi aliran darah (IAD). Namun, angka kepatuhan cuci tangan tenaga kesehatan masih belum optimal, khususnya di Unit Neonatal. Program edukasi terhadap tenaga kesehatan dilakukan untuk meningkatkan kepatuhan cuci tangan.

Tujuan. Mengetahui hubungan kepatuhan cuci tangan tenaga kesehatan terhadap kejadian IAD di Unit Neonatal sebelum dan setelah edukasi.

Metode. Studi dengan desain potong lintang dilakukan di Unit Neonatal RSUPN Dr. Cipto Mangunkusumo (RSCM) periode Juli 2012-September 2014 sebelum dan setelah edukasi.

Hasil. Rerata kepatuhan cuci tangan 68\%, dengan kepatuhan tertinggi adalah perawat (69\% sebelum edukasi dan $72,5 \%$ setelah edukasi), sedangkan terendah adalah petugas laboratorium (22\%). Tingkat kepatuhan cuci tangan di unit level 2 lebih tinggi (73\%) daripada level $3(68,5 \%)$. Kepatuhan cuci tangan tenaga kesehatan terhadap kejadian IAD baik sebelum dan setelah edukasi tidak bermakna secara statistik (nilai $\mathrm{p}>0,05$ ).

Kesimpulan. Tidak terdapat hubungan antara kepatuhan cuci tangan tenaga kesehatan terhadap kejadian IAD di Unit Neonatal sebelum dan setelah edukasi. Sari Pediatri 2017;18(6):443-7

Kata kunci: kepatuhan cuci tangan, infeksi aliran darah, unit rawat neonatal

\section{The Correlation Hand Hygiene Compliance and Bloodstream Infection Rate in Neonatal Unit Before and after Hand Hygiene Education}

Mustarim, Rinawati Rohsiswatmo

Background. Hand hygiene is one of the most effective and simple practice strategy recommended by WHO to reduce HAI-BSI rate. Unfortunately, hand hygiene compliance of medical staff was not optimalized, specially in neonatal unit. Educational program of health care supposed to be increase hand hygiene compliance.

Objective. To analyse the correlation between hand hygiene compliance and bloodstream infection case in neonatal unit RSCM before and after hand hygiene education

Methods. Cross sectional study design was used. Hand hygiene compliance and bloodstream infection data was collected retrospectively during July 2012 until September 2014.

Results. Average of health care hand hygiene compliance in neonatal unit is 68\%, which is the highest is nurses (69\% before and $72,5 \%$ after education), and doctors (65\% before and $45 \%$ after education), the lowest hand hygiene compliance is laboran (22\%). The hand hygiene compliance in $2^{\text {rd }}$ level $(74 \%)$ is higher than $3^{\text {nd }}$ level $(71 \%)$. There is no signifficant stastical correlation between hand hygiene compliance and bloodstream infection case in neonatal unit $(\mathrm{p}>0.05)$.

Conclusion. There are no signifficant correlation between hand hygiene compliance and bloodstream infection, including before and after the hand hygiene educational programs in neonatal unit. Sari Pediatri 2017;18(6):443-7

Keywords: hand hygiene compliance, bloodstream infection, neonatal unit

Alamat korespondensi: dr. Mustarim Sp.A, Divisi Perinatologi Departemen Ilmu Kesehatan Anak Universitas Indonesia, Jl. Diponegoro no 71 Jakarta. E-mail: mustarim12@yahoo.com 


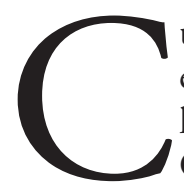

uci tangan adalah salah satu strategi efektif dalam upaya menurunkan angka kejadian infeksi aliran darah (IAD). ${ }^{1,-7}$ Organisasi kesehatan dunia (World Health Organization/WHO) menganjurkan angka kepatuhan cuci tangan tenaga kesehatan sebaiknya mencapai $85 \%{ }^{4,5}$ Namun kenyataannya, kepatuhan mencuci tangan tenaga kesehatan masih sangat bervariasi antara 5 hingga $89 \%$ dengan rerata $38,7 \% .^{2-4}$ Oleh sebab itu, berbagai instansi mengupayakan berbagai cara untuk meningkatkan kepatuhan cuci tangan tenaga kesehatan dengan memberikan program pelatihan dan edukasi. Penelitian sebelumnya menunjukkan bahwa terdapat perbedaan rerata angka kepatuhan cuci tangan tenaga kesehatan sebelum dan setelah edukasi kebersihan tangan. ${ }^{1-3,6}$ Program ini telah coba diterapkan di unit rawat neonatal RS Dr. Cipto Mangunkusumo (RSCM) sejak bulan Juli tahun 2012, edukasi terhadap tenaga kesehatan dipilih dengan metode pengajaran dan pelatihan structured, clinical, objective-referenced, problemoriented, integrated organised (SCORPIO). Metode pengajaran dan pelatihan ini merupakan edukasi multidisiplin yang diperkenalkan dalam program internasional South East Asia - Using Research for Change in Hospital-acquired Infection in Neonates (SEA URCHIN). ${ }^{7}$ Negara peserta SEA URCHIN, termasuk Indonesia, Filipina, Malaysia dan Thailand, diikutsertakan dalam pelatihan ini untuk mengajar dan melatih para tenaga kesehatan di negara masingmasing, kemudian dievaluasi dan ditindaklanjuti seberapa besar metode ini mampu memengaruhi angka infeksi di unit perawatan tersebut. Program edukasi ini bertujuan untuk meningkatkan ilmu pengetahuan, keterampilan, dan motivasi untuk melakukan praktik cuci tangan sehingga berkorelasi dalam meningkatkan kepatuhan tenaga kesehatan RSCM. Metode pelatihan SCORPIO ini tediri atas pelatihan dengan 4 skill station dengan 5-7 orang peserta setiap kelompok, waktu 30 menit antar station, setelah itu dilakukan ujian tulis dan OSCE serta feed back. ${ }^{7}$ Penelitian ini bertujuan untuk melihat hubungan antara kepatuhan cuci tangan tenaga kesehatan dengan angka kejadian IAD sebelum dan setelah edukasi, membandingkan kepatuhan cuci tangan unit rawat neonatal level 3 dan level 2, juga mengetahui hubungan kepatuhan cuci tangan dan kejadian IAD di unit rawat neonatal RSCM sebelum dan setelah edukasi kebersihan tangan.

\section{Metode}

Penelitian dengan desain potong lintang dengan sampel seluruh data kepatuhan cuci tangan dan kejadian IAD yang dikumpulkan dari PPIRS (pencegahan dan pengendalian infeksi rumah sakit) RSCM Juli 2012 hingga September 2014. Tenaga kesehatan yang kontak secara langsung maupun tidak terhadap bayi-bayi sakit di unit neonatal, meliputi dokter, perawat, petugas laboratorium, dan petugas kebersihan diaudit oleh auditor (perawat unit neonatal yang telah diajar dan dilatih praktik cuci tangan yang baik dan benar sesuai rekomendasi WHO dengan metode SCORPIO). Audit kepatuhan cuci tangan dilakukan setiap bulan pada waktu yang ditentukan oleh tim auditor, umumnya selama 30 menit, menggunakan formulir yang sudah disepakati secara internasional kemudian direkapitulasi dan dikumpulkan ke bagian PPIRS dan diolah sebagai data bulanan.

Kriteria diagnosis IAD yang digunakan adalah gejala klinis infeksi nyata yang disertai dengan hasil laboratorium penanda sepsis yang meningkat dan telah dikonfirmasi dengan hasil kultur darah positif (cultureproven sepsis). Analisis statistik dilakukan dengan uji korelasi Spearman, dengan tingkat kemaknaan $\alpha=0,05$.

\section{Hasil}

Sampel data yang diambil adalah selama 2 tahun, 12 bulan sebelum dan 12 bulan setelah edukasi. Dibandingkan antara dokter, perawat, petugas laboratorium dan petugas kesehatan yang kontak secara langsung maupun tidak langsung dengan bayi sakit di Unit Rawat Neonatal RSCM. Berdasarkan data audit kepatuhan cuci tangan, rerata kepatuhan 68\% (69\% sebelum dan 67\% setelah edukasi). Kepatuhan tenaga kesehatan yang paling memengaruhi total kepatuhan adalah profesi dokter [kekuatan korelasi $(\mathrm{r})=0,753, \mathrm{p}=0$ ], diikuti dengan kepatuhan perawat SCN $4(\mathrm{r}=0,612, \mathrm{p}=0)$, sedangkan kekuatan korelasi kepatuhan petugas kebersihan tergolong lemah $(r=0,167)$, dan petugas laboratorium tergolong sangat lemah $(r=0,067)$.

\section{Pembahasan}

Perilaku cuci tangan di kalangan tenaga kesehatan telah diakui sebagai salah satu strategi efektif, efisien, praktis, 
Mustarim dkk: Kepatuhan cuci tangan terhadap kejadian IAD sebelum dan setelah edukasi

Tabel 1. Karakteristik audit kepatuhan cuci tangan sebelum dan setelah edukasi

\begin{tabular}{|c|c|c|c|c|}
\hline \multicolumn{2}{|l|}{ Variabel } & \multicolumn{2}{|c|}{$\begin{array}{c}\text { Sebelum edukasi } \\
(\%)\end{array}$} & Setelah edukasi (\% \\
\hline \multicolumn{2}{|l|}{ Dokter } & \multicolumn{2}{|c|}{65} & 45 \\
\hline \multicolumn{2}{|l|}{ Petugas kebersihan } & \multicolumn{2}{|c|}{36} & 32 \\
\hline \multicolumn{2}{|l|}{ Petugas laboratorium } & \multicolumn{2}{|c|}{22} & 22 \\
\hline \multicolumn{2}{|l|}{ Perawat level 2} & \multicolumn{2}{|c|}{72} & 74 \\
\hline \multicolumn{2}{|l|}{ Perawat level 3} & \multicolumn{2}{|c|}{66} & 71 \\
\hline \multicolumn{2}{|l|}{ Total kepatuhan cuci tangan } & \multicolumn{2}{|c|}{69} & 67 \\
\hline \multicolumn{5}{|c|}{ Total kepatuhan cuci tangan 5 kesempatan rekomendasi WHO } \\
\hline \multicolumn{2}{|c|}{ Sebelum kontak dengan pasien } & \multicolumn{2}{|c|}{70} & 90 \\
\hline \multicolumn{2}{|l|}{ Sebelum melakukan prosedur aseptik dan invasif } & \multicolumn{2}{|c|}{76} & 62 \\
\hline \multicolumn{2}{|l|}{ Setelah terkena cairan tubuh pasien } & \multicolumn{2}{|c|}{39} & 87 \\
\hline \multicolumn{2}{|l|}{ Setelah kontak dengan pasien } & \multicolumn{2}{|c|}{64} & 67 \\
\hline \multicolumn{2}{|c|}{ Setelah kontak dengan lingkungan } & \multicolumn{2}{|c|}{53} & 36 \\
\hline \multicolumn{5}{|c|}{$\begin{array}{l}\text { Keterangan : NICU - neonatal intensive care unit, SCN - special care nursery 1,2,3,4. Perawatan level 3: NICU dan SCN1. Perawatan level 2: } \\
\text { SCN2, 3, dan } 4\end{array}$} \\
\hline \multicolumn{5}{|c|}{ Tabel 2.Hubungan IAD dan kepatuhan cuci tangan sebelum dan setelah edukasi } \\
\hline $\begin{array}{cc}\text { Edukasi } \\
\text { kebersihan } \\
\text { tangan }\end{array}$ & $\begin{array}{c}\mathrm{N} \\
\text { (bulan) }\end{array}$ & & SD & $\mathrm{p}^{*}$ \\
\hline \multirow[t]{2}{*}{ Insidens rate IAD (permil) } & 12 & $12 \%_{0}$ & 3.22035 & 0,288 \\
\hline & 12 & $10 \%_{0}$ & 3.52150 & \\
\hline \multirow[t]{2}{*}{ Total kepatuhan cuci tangan } & 12 & $69 \%$ & .121393 & 0,738 \\
\hline & 12 & $67 \%$ & .142659 & \\
\hline
\end{tabular}

*IAD = infeksi aliran darah

dan sederhana untuk mengurangi angka infeksi di rumah sakit, termasuk IAD. ${ }^{1-7}$ Berdasarkan analisis data periode Juli 2012 sampai dengan Juni 2013 (sebelum edukasi) dan Juli 2013 hingga September 2014 (setelah edukasi), terdapat perbedaan rerata kepatuhan cuci tangan sebelum dan setelah edukasi. Kepatuhan cuci tangan meningkat setelah edukasi, tenaga kesehatan mempunyai kesadaran dan motivasi yang lebih baik sehingga menjadi lebih patuh cuci tangan. Namun, perlu kita sadari bahwa terdapat berbagai faktor lain yang juga berperan selain edukasi, antara lain faktor kebiasaan, bukan hal yang mudah untuk mengubah kebiasaan tenaga kesehatan. Dibutuhkan durasi waktu yang lebih lama untuk menjadikan cuci tangan sebagai kebiasaan setelah edukasi ini diberikan. Hal ini bisa menjadi landasan mengapa masih bervariasinya angka kepatuhan cuci tangan, walaupun edukasi telah diberikan. ${ }^{2,8}$ Selain itu, WHO (2009) menyatakan bahwa terdapat berbagai hal yang memengaruhi kepatuhan cuci tangan, bukan hanya faktor edukasi, melainkan faktor lain juga berperan, seperti kurangnya role model, faktor alergi/iritasi pada tangan, dan lain lain. ${ }^{5}$

Dari keseluruhan analisis data diperoleh bahwa tidak ada perbedaan antara kepatuhan cuci tangan sebelum dan setelah edukasi. Penelitian ini berbeda dengan penelitian Pittet $^{6}$ tahun 2001, penelitian multisenter oleh Aboelela dkk ${ }^{10}$ tahun 2007, dan $\mathrm{Wu}^{9}$ pada tahun 2008 yang melaporkan bahwa program edukasi dan multidisiplin mampu meningkatkan kepatuhan setelah tenaga kesehatan diberikan edukasi.

Kepatuhan cuci tangan, baik sebelum maupun setelah edukasi, tertinggi adalah perawat, diikuti oleh dokter. Sebaliknya, kepatuhan cuci tangan terendah adalah petugas laboratorium. Tidak terdapat perbedaan kepatuhan petugas laboratorium, baik sebelum maupun setelah edukasi. Data kepatuhan ini hampir serupa dengan hasil penelitian yang dilakukan oleh Neves $\mathrm{dkk}^{12}$ di Brazil pada tahun 2006, kepatuhan 
tertinggi adalah dokter, diikuti perawat, dan terendah pada petugas laboratorium. Rupp dkk, ${ }^{13}$ di Nebraska, uga melaporkan angka kepatuhan cuci tangan tertinggi pada perawat dan dokter. Perbedaan kepatuhan antara masing-masing pekerjaan kemungkinan juga disebabkan oleh paparan perawat terhadap pasien yang terus menerus sehingga kesempatan mencuci tangan lebih tinggi daripada profesi lainnya. ${ }^{5}$ Penilaian audit kepatuhan yang dinilai apakah tenaga kesehatan mengerti indikasi kebersihan tangan dan kesempatan melakukan kebersihan tangan, tetapi tidak dinilai apakah langkah-langkahnya sudah benar. Apabila mencuci tangan tidak efektif maka masih mungkin didapatkan mikroorganisme di tangan, yang secara potensial dapat mentransmisikan penyakit. ${ }^{13-15}$ Kepatuhan perawat setelah edukasi pada level 2 lebih tinggi (74\%) daripada level 3 (71\%).

Terdapat hubungan antara kepatuhan cuci tangan pada level 3 dan level 2 terhadap total angka kepatuhan cuci tangan. Besarnya kekuatan korelasi kepatuhan cuci tangan di ruang perawatan level 2 lebih kuat daripada kepatuhan cuci tangan di level 3. Adanya perbedaan kepatuhan cuci tangan perawat ini dapat disebabkan beberapa factor, antara lain, ilmu pengetahuan, masa kerja perawat, motivasi, maupun faktor kepadatan pasien di level 2 dan rasio perawat dan pasien yang tidak ideal dan tidak sesuai dengan standar AAP dan ACOG. ${ }^{16} \mathrm{Hal}$ ini berbeda dengan hasil penelitian sebelumnya yang dilakukan oleh Suryoputri $\mathrm{dkk}^{17} \mathrm{di}$ Semarang yang melaporkan bahwa tidak ada perbedaan kepatuhan cuci tangan tenaga kesehatan di antara ruangan yang berbeda.

Demikian pula hal yang harus kita perhatikan adalah penyebab IAD pada bayi baru lahir multifaktorial. Jadi bukan hanya disebabkan kepatuhan cuci tangan, faktor lain seperti faktor ibu dan kondisi bayi baru lahir lebih rentan infeksi, dapat terjadi karena penggunaan antimikroba yang irasional, ${ }^{18}$ imunodefisiensi, bayi baru lahir sakit yang memerlukan prosedur dan peralatan invasif, perlindungan terhadap flora endogen masih terbatas, fungsi barrier kulit belum optimal, dan adanya paparan antibiotik spektrum luas. ${ }^{19}$ Rojas $\mathrm{dkk}^{20}$ melaporkan beberapa faktor pejamu yang telah terbukti menjadi faktor risiko IAD adalah prematuritas dan berat badan lahir rendah.

Berdasarkan teori strategi untuk mempelajari perilaku baru, terdapat beberapa langkah yang harus dilakukan untuk menerima perilaku baru. Indikator spesifik untuk memantau progresifitas setiap langkah, antara lain, (1) menciptakan kepedulian, (2) mengadopsi konsep, (3) menganggap kepemilikan, (4) bukti praktik, (5) bukti rutin dan terintegrasi, (6) mempertahankan praktik, dibutuhkan waktu 1 tahun atau lebih setelah edukasi untuk menjadi kebiasaan. ${ }^{20-22}$ Oleh sebab itu, edukasi harus lebih giat dilakukan agar dapat meningkatkan kepatuhan cuci tangan dan menjadikan cuci tangan sebagai suatu kebiasaan tenaga kesehatan yang rutin dilakukan sehingga nantinya dapat menurunkan kejadian IAD.

\section{Kesimpulan}

Tidak terdapat hubungan kepatuhan cuci tangan sebelum dan setelah edukasi dengan kejadian IAD, walaupun ada perbedaan tingkat kepatuhan cuci tangan sebelum dan setelah edukasi. Angka kepatuhan cuci tangan tertinggi adalah perawat, dan terendah pada petugas laboratorium. Tingkat kepatuhan cuci tangan perawat di level 2 lebih tinggi daripada level 3 .

\section{Daftar pustaka}

1. Polin RA. Strategyes for prevention of health care- Associated infection in NICU. Pediatrics 2012;129:e1085-e93.

2. Harbarth S, Pittet D, Grady L, Goldmann DA. Compliance with hand hygiene practice in pediatric intensive care. Pediatr Crit Care Med 2001;2:311-4.

3. Pittet D, Huginnet S, Harbarth S. Effectiveness of a hospitalwide programme to improve compliance with hand hygiene. Infection Control Programme. Lancet 2000;356:1307-12.

4. Teare L, Cookson B, Stone S. Hand hygiene. Br Med J 2001;323:411-2

5. WHO. First global patient safety challenge clean care is safer care. World Health Organization. WHO Guidelines on hand hygiene in health care: a summary. Diakses pada 10 April 2017. Diunduh dari: http://whqlibdoc.who.int.

6. Pittet D. Improving adherence to hand hygiene practice a multidisciplinary approach. Emerg Infect Dis 2001;7:234-40.

7. Structured, Clinical, Objective-Referenced, ProblemOriented, Integrated, Organised (SEA URCHIN) Clinical educator Manual. Introduction. 2013

8. Haas JP, Larson EL. Measurement of compliance with hand hygiene. J Hosp Infect 2007; 66:6-14.

9. Wu X. Nursing staff compliance with hand hygiene protocol in NICU in regional perinatal center. New York Medical College 2008;2;75-6. 
10. Aboelela SW, Stone PW, Larson EL. Effectiveness of bundled behavioural interventions to control healthcare-associated infection: a systematic review of the literature. J Hosp Infect 2007;66:101-8.

11. Australian Infection Control Association. Bloodstream Infection (BSI) Definition. AICA 2004;1-9.

12. Neves ZCP, Tipple AFV, Souza ACS, Pereira MS, Melo DS, Ferrira LR. Hand Hygiene : the Ompact of incentive strategies on adherence among healthcare workers from a newborn intensive care unit. Rev Latino-am enfermagem. 2006;14:54652.

13. Rupp ME, Fitzgerald T, Puumala S, Anderson JR, Craig R, Iwen PC, dkk. Prospective, controlled, cross-over trial of alcohol-based hand gel in critical care units. Infect Control Hosp Epidemiol 2008;29:8-15.

14. Pessoa-Silva CL, Hugonnet S, Pfister R, Touveneau S, Dharan S, Posfay-Barbe K, dkk. Reduction of health care-associated infection risk in neonates by successful hand hygiene promotion. Pediatrics 2007;120:e382-90.

15. Simmon B, Bryant J, Neiman K, Spencer L, Arheart K. The role of handwashing in prevention of endemic intensive care unit infections. Infect Control Hosp Epidemiol 1990;11:58994.

16. Association of Women's Health, Obstetric and Neonatal Nurses. Guidelines for Professional Registered Nurses Staffing for Perinatal Units. Diakses pada 10 April 2017. Diunduh dari: http://www.awhonn.org.

17. Suryoputri AD, Ibandrio B. Perbedaan angka kepatuhan cuci tangan tenaga kesehatan di RSUP Dr. Kariadi Semarang, skripsi. Semarang: Fakutas Kedokteran Universitas Diponegoro, 2011

18. Murni IK, Duke T, Kinney S, Daley AJ, Soenarto Y. Reducing hospital-acquired infections and improving the rational use of antibiotics in a developiing country: an affectiveness study. Arch Dis Child 2014:1-6.

19. Pattinson RC. MRC maternal an infant health care strategies research unit.F,V\&V in Obgyn 2010:2:217-8.

20. Rojas MA, Efird MM, Lozano JM, Bose CL, Rojas MX, Rondon MA. Risk factors for nosocomial infections in selected neonatal intensive care units in Colombia, South Am J Perinatol 2005;25:537-41. 